Gazi University
Journal of Science
http://dergipark.gov.tr/gujs

\title{
A Symmetrical-Asymmetrical Fault Characteristics Analysis within Cogeneration Power Plant in Izmir, Turkey: An Experimental Assessment
}

\author{
Hacer SEKERCI OZTURA (D), Sezai POLAT * (D) \\ Electrical and Electronics Engineering Department, Engineering Faculty, Yaşar University, 35100, Izmir, Turkey
}

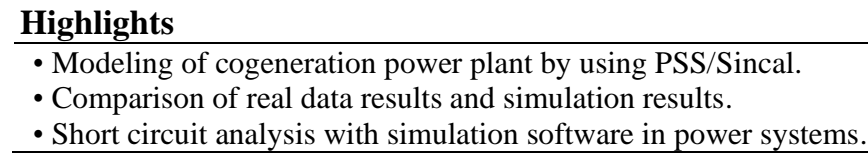

\section{Article Info}

Received: 17 July 2020 Accepted: 19 Apr 2021

\section{Keywords}

Fault calculation Power systems analysis Short circuit Result analysis PSS/Sincal

\begin{abstract}
The analysis of the short circuit should be understood very well in order to make correct designs in the power systems such as the safety of the personnel and the equipment, the selection of the safety relays, the circuit breaker selection and the selection of the appropriate conductor section. In this study, the parameters about the short circuit and the techniques of calculating the faults in system and the necessary theoretical knowledge for the short circuit fault to be understood better have been given. The effect on the distributed generation and the grid which is caused by the possible short circuit faults have been simulated by being modeled in PSS/Sincal and by using the real grid parameters with cogeneration power plant in Izmir, Turkey. The real short circuit fault results measured from the power plant and the grid and the results obtained from the software program have been compared and it has been determined that there is not a significant difference between them. Thus, it has been emphasized that it is correct to simulate before investing in a power system in for the purpose of restrain the faults during the designing and working before the application. It allows the designer to design new power plant as good as plan expansion of existing power plants with higher degree of precision. Considering the prices of protection equipment, which has a large part in system design, this way would allow designer to reduce the cost of the protective equipment and remaining stability.
\end{abstract}

\section{INTRODUCTION}

It is known that electricity is one of the main necessities in human life. The requirements in human life have increased continuously and have been related to the energy demands. The need to find different energy supply methods and energy resources has emerged in order to meet the energy needs. A new concept has emerged in order to use energy efficiency and different resources. Dissimilar, the conventional centralized generation, distributed generation (DG) aims a strategy in which a part of the electric power is produced and transmited to clients with small production units allocated near to the burdens[1-4]. The widespread use of DG not only increases economic efficiency, but also benefits improvements in energy reliability [5]. DG could be operated isolated mode (off grid) or grid connected (on-grid) [6-9].

For a power system to be practical it must be safe, reliable and economical. Thus many analysis must be performed to design and operate an electrical system [10,11]. The widespread use of the energy resources mentioned above causes many power systems issues [12]. For this reason, the design of power systems using DG becomes very important. An analysis of the effects of parameters such as losses, bus voltages and short-circuit fault currents with their connection to the grid is seen in [13]. Fault analysis is a prime apprehension in power system [14]. Power plants must be secured against failures or malfunction in 
order to ensure the qualification and stability of the production, transmission and delivery of power system [15].

In the literature, there are many studies that showed the changes in current and voltage during short circuit which bases on the basis of power system design. Some authors used for demonstrating fault simulation studies and analyses on the IEEE-9 bus [16-18], IEEE-14 bus [19] and 39-bus New England System [18], while other authors examined modeled real data based on which are substation in Turkey [20], substation in India [21], wind power plant [17], nuclear power plant [22]. There are many software in the literature that are widely used to perform short circuit analysis, which are Matlab [16,19,20,23], PSCAD [24], Power World Simulator [25,26], ETAP [17,18,21,27] and DigSilent [22,28]. As a result of calculating short circuit currents, there are studies for the selection of the protection equipment and determination of the coordination scheme of the protection equipment. Different algorithms, heuristic optimizations and adaptive methods are proposed on the coordination scheme for protection method $[17,18,23]$. Protection coordination and methods are out the scope of this study. The use of current limiter emerges as a different protection method. [16] aimed to find optimal placement of current limiter in a power system against the short circuit faults. In other study on short circuit analysis, [29] showed the changes in current and voltage during short circuit issue for protection scheme in micro grid by using PSCAD. [30] proposed fault detection scheme used transient current by using Discrete Fourier transform. [31] demonstrated contribution of short circuit current scenarios inverter-based voltage source DG for on-grid system. Unlike alternating current (AC) systems, in another study, [32] proposed method used CIGRE benchmark high voltage direct current (HVDC) model by using PSCAD software for direct current (DC) system. In another study on fault analysis, [33] suggested fault location that used partial differential equations by using adomian decomposition method in Matlab. The authors investigated power protection systems in nuclear power plant in [34].

This paper aims to variation and determines short circuit currents, because simulation results are validated with measured data of actual fault condition. It allows to decision expansion of existing power plants as minimum cost protection devices.

In this study, the system is modeled using the parameters of a real cogeneration power plant by using Power System Simulator Siemens Network Calculator (PSS/Sincal) software. The simulation results obtained for the fault generated in the system modeled were compared to the measured current and voltage waveforms as a result of a single phase fault occurring in the past. After validating the accuracy of current and voltage changes that occur in real fault situations, other fault conditions which are single phase, two phase, three phase ground faults in grid connected and two phase ground fault in island mode faults that may occur in a power system were simulated, and voltage and current changes occurring in the power system during the generated faults were observed.

\subsection{Contribution}

There are many studies in the literature involving short circuit analysis. These studies have contributed to the literature with methods such as different algorithms, procedures and software. Recently, when the effects of short circuit fault on the distribution power system are analyzed, it is seen that it is generally done by considering the distribution generation systems integrated into the test systems. Fault analyzes performed in the distribution power network are generally conducted with the IEEE 13-node and IEEE 34node test systems. On the other hand, there are very few studies that model the systems belonging to the existing power plant. With the increase in the use of renewable energy, power plants with stochastic character such as solar and wind have been examined as distributed generation in test systems. However, there are a few studies the distributed generation system, which includes cogeneration power plants, which is the subject of this study, which is widely used in the industry. Similarly, although programs such as PCAD, DgSilent, ETAP, which are widely used in the literature for short circuit analysis, are quite common, PSS/Sincal has been used very little. Although PSS/Sincal is used in many applications in industry, it is seen that it is used in limited numbers in the literature. The major contribution of this research paper is mentioned below. First, with this study, it is tried to contribute to the literature by analyzing the short circuit of the cogeneration power plant, which is widely used in the industry, using the PSS/Sincal program, 
making a unique study in the literature. Second, the uniqueness of this study is that an existing system is modeled and then different possible scenarios and faults are occurred in the power plant. Third, the real fault records in the existing power plant are examined, and the same system is compared with the fault currents modeled in the software, and it is revealed that there is no significant difference in terms of design and equipment selection. This paper concerns the by modeling with the cogeneration power plant PSS/Sincal software, researchers are introduced to the literature by introducing a new perspective and method.

\subsection{Organization of The Paper}

This paper contains total 6 Chapters. Chapter 1, after a brief introduction, literature view and contribution are presented in this chapter. Chapter 2 and Chapter 3 show information about distributed generation technologies and cogeneration power plant respectively. In Chapter 4, it is been illustrated short circuit analysis basic knowledge. Calculation method of fault currents is given in Chapter 5. In Chapter 6, it is introduction and modeling in simulation software. The case studies are given in Chapter 7. Finally, conclusions are drawn in Chapter 8.

\section{DISTRIBUTED GENERATION TECHNOLOGIES}

The distributed generation technologies are divided as traditional and nontraditional. The definitions of some of the distributed generations used most commonly are given below Figure $1[35,36]$.

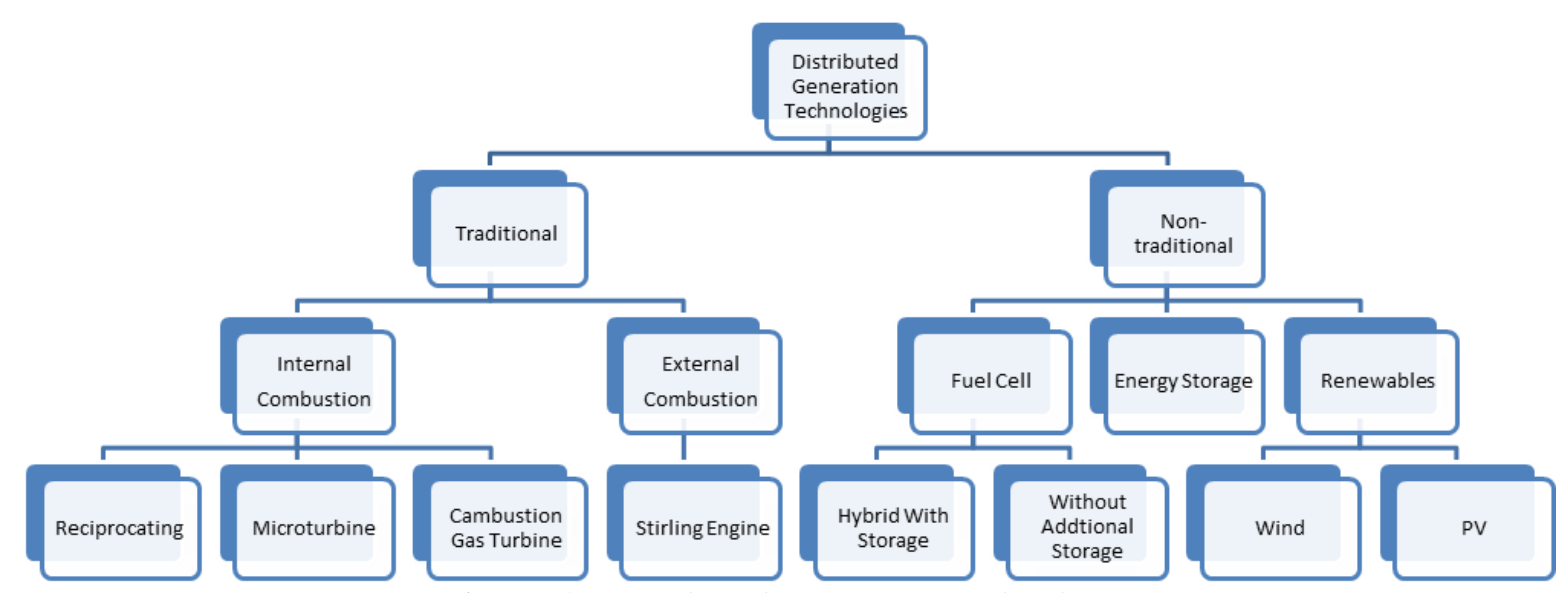

Figure 1. Distributed generation technologies

\subsection{Applications and Advantages}

The distributed generation is used to increase the reliability, stability and power quality of the power system while boosting to grid by decreasing congestions in medium and high voltage level lines. Thus, it has benefits for the producer and the consumer. By using today's energy resources in DG, low cost energy production and high quality electricity can be provided. In addition, when the energy used for production and commercial purposes is interrupted, the major financial damages that occur are prevented. Several pros and cons that occur when using distributed generation are given Table 1 [37-39].

Table 1. Some of the DG pros and cons

\begin{tabular}{|c|c|c|}
\hline Pros for the customer & Pros for the producer & Cons for customer and producer \\
\hline $\begin{array}{l}\text { - Improved reliability, } \\
\text { - Improved power quality, } \\
\text { - Reduction in the interruption } \\
\text { number, } \\
\text { - Efficient use of energy, } \\
\text { - Lower cost of energy, } \\
\text { - Usage of green energy sources, }\end{array}$ & $\begin{array}{l}\text { - Decreased line losses, } \\
\text { - Raised up the system capacity } \\
\text { - Enhanced stability, } \\
\text { - Prolong tool life, } \\
\text { - Decreased congestion, } \\
\text { - Enhanced voltage profile }\end{array}$ & $\begin{array}{l}\text { - Extremely fault current, } \\
\text { - Raised up the protection charge } \\
\text { - Probability of off-grid mode, } \\
\text { - Increased flicker, } \\
\text { - Probability of over voltage, } \\
\text { - Retrofitting charge }\end{array}$ \\
\hline
\end{tabular}




\begin{tabular}{|l|l|l|}
\hline- Decreased pollution & $\begin{array}{l}\text { - Enhanced weak signal stability, because of } \\
\text { slight of inertia, } \\
\text { - Improved critical clearance period. }\end{array}$ & \\
\hline
\end{tabular}

Short circuit currents, which are one of the disadvantages of distributed generation, are the subject of this paper. As seen in the Table 1 above, increasing of short circuit currents are seen despite many benefits. It is seen that short circuit levels in the system increase due to the contribution of short circuit currents to be provided by the generators in the production facility $[12,40-42]$.

\section{COGENERATION POWER PLANT}

The demand increase, the price increase and the reliability decrease and so on, most of the industrial plants have shifted away towards generating their own power instead of purchasing electricity from centralized generations. However, besides the electricity need of the factory, there may be a need for hot water. Cogeneration can serve an appealing alternative for offices with high electric rates and buildings that utilize huge amounts of hot water and power. As a rule, the higher the electric rates, the more noteworthy the savings with cogeneration and the lower the back pay time [43].

At first, the heat energy is change over to the rotational energy and after that it is converted to the electricity energy via the shaft and the generator integrated. The converted electrical energy is given to the electricity distribution system at the $34.5 \mathrm{kV}$. In this study, electricity production and electrical distribution is carried out with the $34.5 \mathrm{kV}$ voltage level.

In this paper, different faults type short circuit currents which are possible to occur in cogeneration power plant in Izmir, Turkey are modeled under PSS/Sincal platform. In the power plant, there are two gas turbines each of which is at 6.5 MVA power that gas turbine coupled to the synchronous type generator. While the produced electricity is at $6.3 \mathrm{kV}$ voltage level, it is converted to the $34.5 \mathrm{kV}$ voltage level by the transformers at 6 MVA of power. If it is needed less energy in the plants, the extra electricity, which is produced, is supplied to the grid. In case of an outage or blackout in the distribution network (grid), the power plant works in island mode (off grid).

\section{SHORT CIRCUIT ANALYSIS}

When a short circuit occurs, the all considered internal impedance replaces components and an equivalent voltage source is implemented at the fault node the equivalent short-circuits impedance of the system electrical system.

Faults are generally divided into two broad categories in today's power systems [19];

- Symmetrical or balanced faults (three phase)

- Asymmetrical or unbalanced faults.

Asymmetric faults such as single phase ground, phase to phase and two phase to ground faults are divided into three major types[44]. Figure 2(I) shows that schematic asymmetrical and unsymmetrical faults are occurred in a power system. The distribution of faults in the electrical system by their types is shown in the Figure 2(II). As can be seen in the Figure 2, the most common single phase fault is seen, whereas the rarest three phase fault is seen. Different fault types scenarios were occurred and short circuit analyzes were conducted out in Chapter 7. 


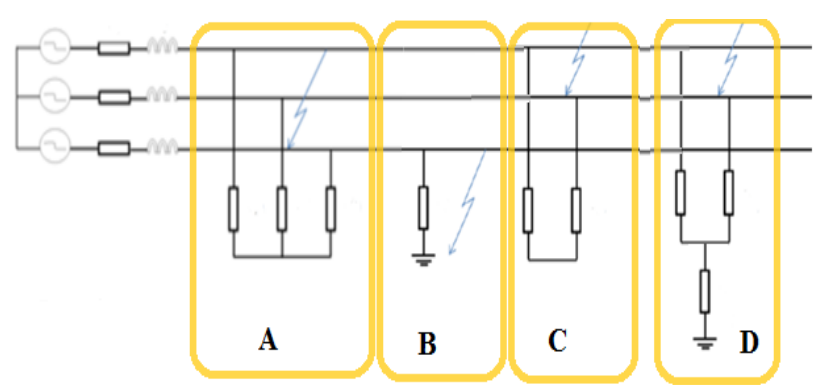

(I)

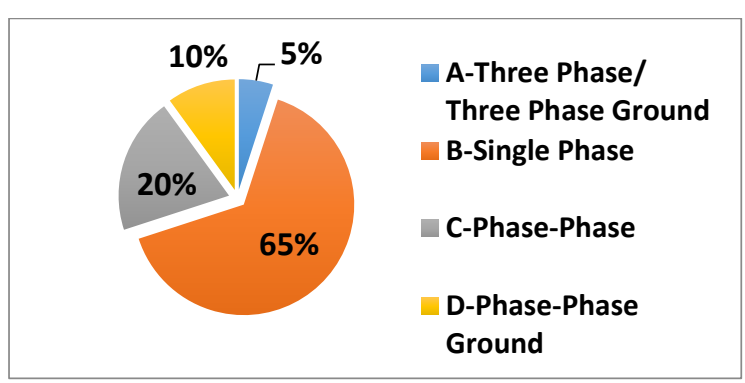

(II)

Figure 2. (I):(A) The three phase, (B) single phase to ground, (C) phase to phase, (D) phase to phase ground faults, (II): The rates of fault types

Short circuit currents, which are one of the disadvantages of distributed generation, are the subject of this paper. As seen in the Table 1, increasing of short circuit currents are seen despite many benefits. It is seen that short circuit levels in the system increase due to the contribution of short circuit currents to be provided by DG units $[12,40-42,45]$. DG's contributions to short circuit fault currents can be divided into two main categories which are synchronous/asynchronous generators and Inverter Based DGs (IBDG) [46]. Since IBDG cannot be overloaded, there are negligible level of fault current contributions compared to synchronous/asynchronous generators [31]. Since a synchronous type generator is used in the cogeneration power plant modeled in this study, a synchronous generator is modeled in calculations and simulation.

\section{CALCULATION METHOD OF FAULT CURRENTS}

Traditional power systems have been replaced by system systems to which many DGs are connected today. It is assumed that there is a fault at point ' $\mathrm{k}$ ' in a network where the network and DG are located. The fault situation occurring at point ' $\mathrm{k}$ ' in the network to which many DGs connected to the network are connected is shown in the Figure $3[47,48]$.

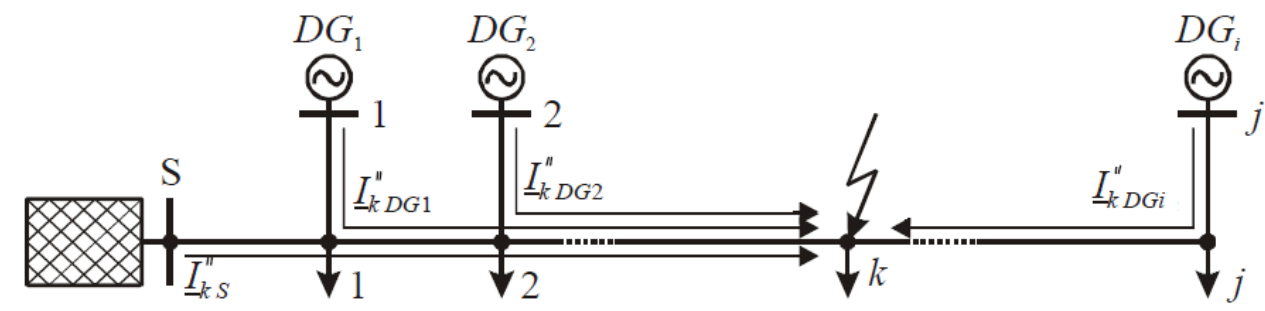

Figure 3. Scheme of fault at distribution or transmission line supplying Grid and DG

Where; $I_{k S}^{\prime \prime}$ is the injected current of grid, $I_{k D G i}^{\prime \prime}$ is the injected currents of DG $(i=1,2,3 \ldots . j)$. With asymmetrical faults, for example single phase ground fault, currents and voltages are not of the same magnitude. The three phase current must be divided into its three symmetrical components: positive, negative and zero phase sequence. This shows that negative, zero and positive phase sequence data are all needed to calculate asymmetrical faults for the equipment. PSS/Sincal calculation methods are based on symmetrical components.

The fault current occurred at the ' $\mathrm{k}$ ' point is calculated with the help of the formulations shown in Table 2 by using the positive, negative and zero sequence value obtained by the symmetrical component transformation method [49]. 
Table 2. The formulates of short circuit currents for " $k$ " point

\begin{tabular}{|c|c|c|c|c|}
\hline & Single Phase Fault & Phase-phase ground fault & Phase-phase fault & Three phase ground fault \\
\hline$I_{k}^{+}$ & $\frac{U_{k a}}{Z_{k}^{+}+Z_{k}^{-}+Z_{k}^{0}}$ & $\frac{\left(Z_{k}^{-}+Z_{k}^{0}\right) U_{k a}}{Z_{k}^{+} Z_{k}^{-}+Z_{k}^{+} Z_{k}^{0}+Z_{k}^{-} Z_{k}^{0}}$ & $\frac{U_{k a}}{Z_{k}^{+}+Z_{k}^{-}}$ & $\frac{U_{k a}}{Z_{k}^{+}}$ \\
\hline$I_{k}^{-}$ & $\frac{U_{k a}}{Z_{k}^{+}+Z_{k}^{-}+Z_{k}^{0}}$ & $\frac{-Z_{k}^{0} U_{k a}}{Z_{k}^{+} Z_{k}^{-}+Z_{k}^{+} Z_{k}^{0}+Z_{k}^{-} Z_{k}^{0}}$ & $-\frac{U_{k a}}{Z_{k}^{+}+Z_{k}^{-}}$ & 0 \\
\hline$I_{k}^{0}$ & $\frac{U_{k a}}{Z_{k}^{+}+Z_{k}^{-}+Z_{k}^{0}}$ & $\frac{\left(Z_{k}^{-}+Z_{k}^{0}\right) U_{k a}}{Z_{k}^{+} Z_{k}^{-}+Z_{k}^{+} Z_{k}^{0}+Z_{k}^{-} Z_{k}^{0}}$ & 0 & 0 \\
\hline
\end{tabular}

$Z_{k}^{+}, \mathrm{Z}_{\mathrm{k}}^{-}$and $\mathrm{Z}_{\mathrm{k}}^{0}$ are Thevenin equivalent circuit impedances seen from the fault point impedances positive, negative and zero sequences, respectively. $U_{\mathrm{ka}}$ is the voltage of fault point in the steady state of the system before fault. $I_{k}^{+}, I_{k}^{-}$and $I_{k}^{0}$ are fault current sequences (positive, negative and zero sequences). The contribution of DG in this obtained fault current to this short circuit currents of each DG are calculated by the Current Divider Method. The contribution of each generator to fault current which is calculated with respect to Table 2 can be obtained by using the current divider method.

Thevenin equivalent circuit of sequence network is obtained easily because of network given in Figure 3 is simple and radial. If the network is loop connection type and has many connection points, Thevenin equivalent impedances cannot be obtained directly, so bus admittance matrix have to be calculated. All fault currents and the bus voltages after than fault occurring can be calculate by using this bus impedance matrix. Figure 4 shows the flow chart of the calculation procedure used by the software for calculating [50].

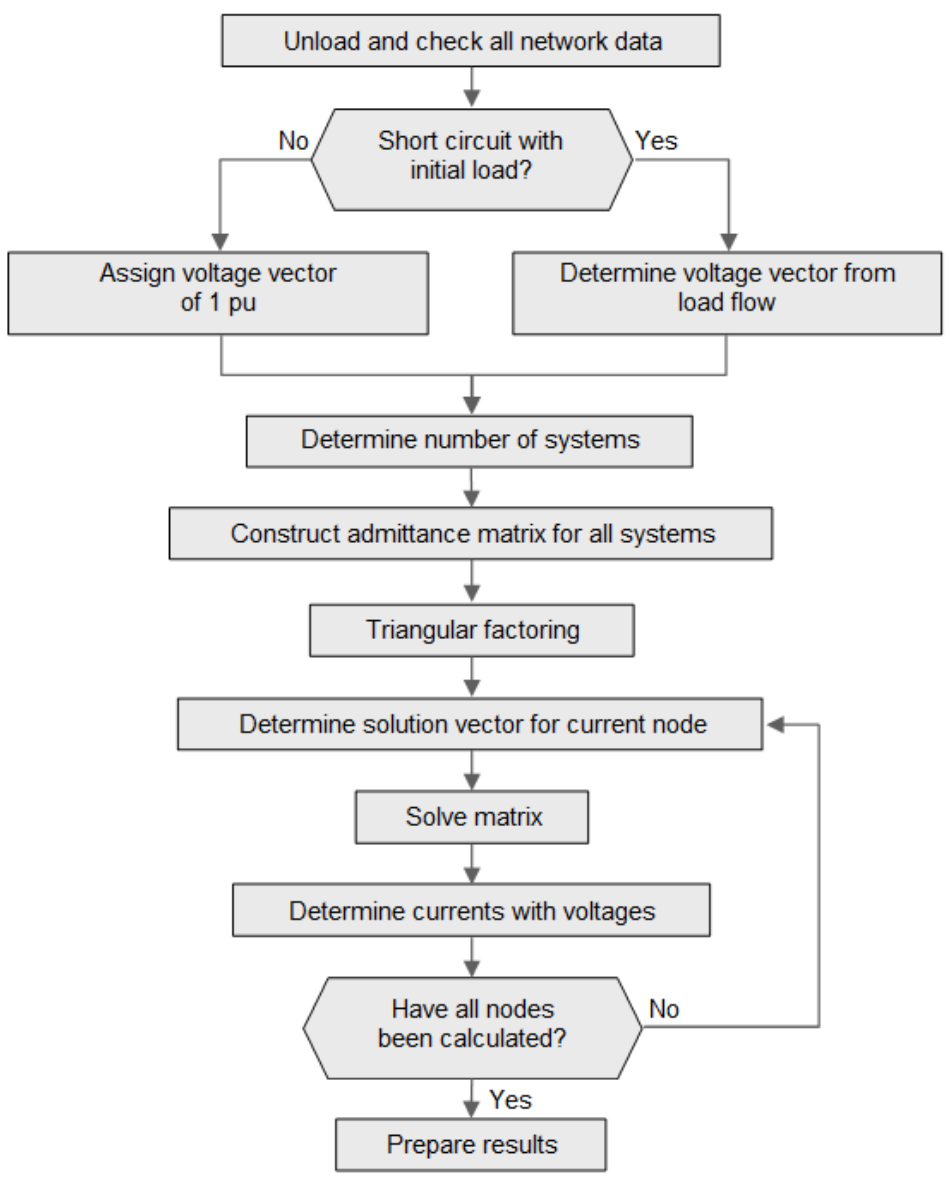

Figure 4. Short circuit calculation procedure 


\section{SIMULATION}

\subsection{Simulation Software}

Power System Simulator Siemens Network Calculator (PSS/Sincal) software has been used for the analysis and simulation in this study. PSS/Sincal is software with designing tools for power system analysis. Power systems analysis includes the short circuit analysis, the power flow, dynamic analysis, harmonic analysis, protection, reliability and contingency analysis. The electromagnetic transients (EMT) let the designer use the differential equations to model networks, machines and controllers. It offers a complete solution for all electromechanical and electromagnetic phenomena, including unsymmetrical sequences [51].

\subsection{Modeling of the Power Plant}

It is utilized that power plant single line diagram is shown in Figure 5 for modeling in simulation tool. Rotating loads, non-rotating loads and other loads were determined in the power plant. The power plant equipments which are system loads, generators, power transformers, lines current transformers, voltage transformers, circuit breakers, other protection and measurement devices are modeled according to the obtained from technical service engineers at the factory and also single line diagram.

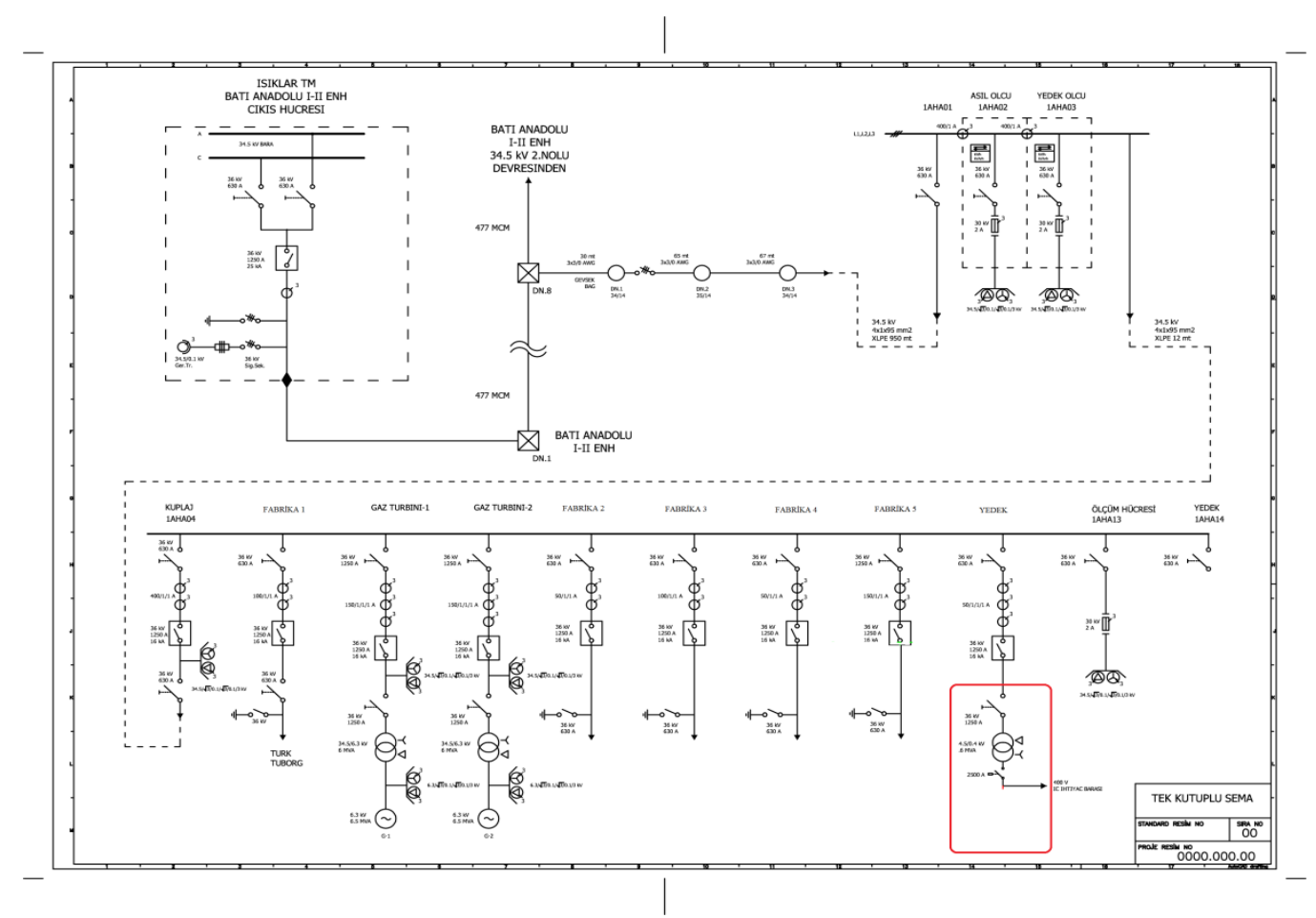

Figure 5. Exist cogeneration power plant single line diagram

In this paper, it is utilized PSS/Sincal for simulation and evaluation of existing cogeneration power plan system. For this purpose, these are represented below the Figure 6 where loads, generators, lines and grid connection point. The modeling has been based on the real loads of the plants, the real power of the transformers, the motors, the generators and the impedance of the lines. 


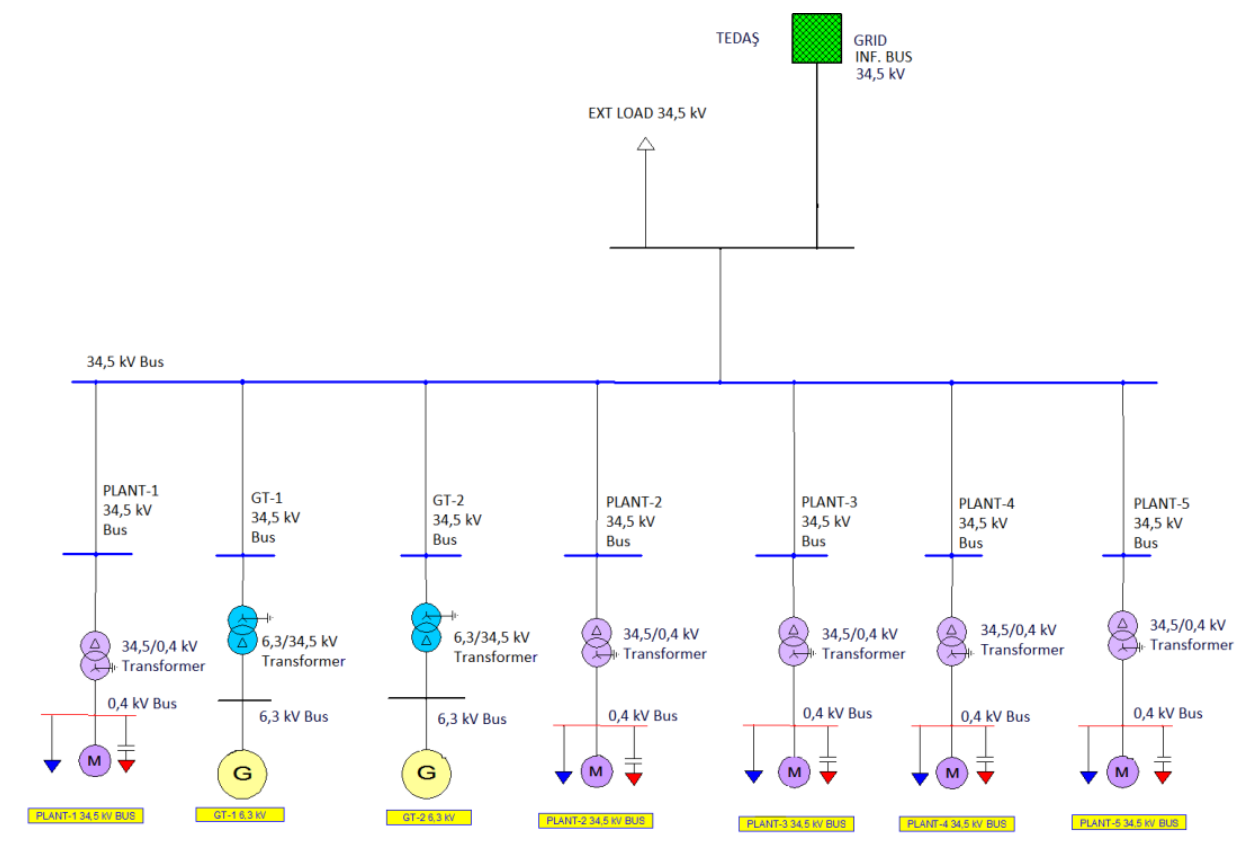

Figure 6. Simulated cogeneration power plant single line diagram

This plant has been modeled as an industrial system including electrical distribution system directly connected to cogeneration power plant and five plants of an industrial zone. The power system is connected to the grid by one line at $34.5 \mathrm{kV}$ voltage at Bat1 Anadolu Power Transmission Line I-II lines. The distribution to the plants is at $34.5 \mathrm{kV}$ voltage level and it is connected with $1 \mathrm{~km} 3(1 \mathrm{x} 95) \mathrm{mm}^{2} \mathrm{XLPE}$ type cable, $200 \mathrm{mt} \mathrm{3 \times 3/0} \mathrm{AWG} \mathrm{and} 2 \mathrm{~km} \mathrm{3 \times 477} \mathrm{MCM} \mathrm{cables.} \mathrm{The} \mathrm{power} \mathrm{plant} \mathrm{has} 2$ Gas Turbines (GT) connected to the same $34.5 \mathrm{kV}$ bus. Each turbine has 6.5 MVA capacity and total power plant production capacity is 13 MVA. The gas turbines are coupled to the synchronous type generator. There is a 6 MVA power rate and 6.3/34.5 $\mathrm{kV}$ step up transformer connected to the each gas turbine. Base on the operating conditions of power plant and facilities, either supplying to grid or getting from the grid is possible. There are 5 plants in industrial zone and each factory is supplied one by one by the cable feeders. All plants have its own step-down transformer $(34.5 \mathrm{kV} / 0.4 \mathrm{kV})$ feeding each $0.4 \mathrm{kV}$ factory bus.

\section{CASE STUDIES}

In this section, the cogeneration power plant is possible three phase ground, phase-to-phase fault considering low voltage side $(0.4 \mathrm{kV})$ and medium voltage $(34.5 \mathrm{kV})$ side has been designed by using $\mathrm{PSS} /$ Sincal. The simulation obtained in the voltage and the current graphs for each fault compared with the real fault conditions have been reviewed and made simulations. The information about the occurred cases, the type of fault, the location of fault, the mode of operation, the starting time and the cleaning fault times are given in Table 3.

Table 3. Case studies

\begin{tabular}{|c|c|c|c|c|c|}
\hline $\begin{array}{c}\text { Real Fault } \\
\text { Condition }\end{array}$ & L1 ground fault & Grid & On grid & $550 \mathrm{~ms}$ & $700 \mathrm{~ms}$ \\
\hline Case1 & L1 ground fault & Grid & On grid & $550 \mathrm{~ms}$ & $700 \mathrm{~ms}$ \\
\hline Case2 & L1, L2 ground fault & Grid & On grid & $200 \mathrm{~ms}$ & $280 \mathrm{~ms}$ \\
\hline Case3 & $\begin{array}{c}\text { L1, L2, L3 } \\
\text { ground fault }\end{array}$ & $\begin{array}{c}\text { Low voltage } \\
\text { side (Plant-3) }\end{array}$ & On grid & $200 \mathrm{~ms}$ & $280 \mathrm{~ms}$ \\
\hline Case4 & L1, L2 ground fault & $\begin{array}{c}\text { High voltage } \\
\text { side (Plant-1) }\end{array}$ & $\begin{array}{c}\text { Off grid } \\
\text { (island mode) }\end{array}$ & $200 \mathrm{~ms}$ & $280 \mathrm{~ms}$ \\
\hline
\end{tabular}


In order to compare the obtained waveform in the simulation results with each other, all bus voltage levels are scaled to be at the $0.4 \mathrm{kV}$ voltage level. The reason for this is that all the data from the power plant was recorded according to the $0.4 \mathrm{kV}$ scale and root mean square (RMS) value. In order to make an accurate graphic comparison, all buses at the voltage level are scaled to $0.4 \mathrm{kV}$ as if it were P.U. (per unit) system. In simulated cases, the locations of faults are given on the single line diagram shown in Figure 7.

Case 1 (simulating the real system): The single phase ground fault circuit occurred at grid at the 550th msec and then the fault was cleared at the 700th msec. The results obtained as a result of the simulation showed that there were different current and voltage oscillations in all buses. After the single phase short circuit had occurred, the voltages of L1 phases sharply dropped to about 200 volt magnitude. The reason why the voltage does not decrease to zero is that the exact location of the fault in the network is unknown. The exact location of the fault could not be obtained from the distribution company. While modeling the system, the location of the fault, a point far from the power plant, was determined approximately. Because the exact fault location was not known, the magnitudes of the measured voltages and currents were different from the obtained simulation. The reason for this was that the loads and impedances changed momentary.

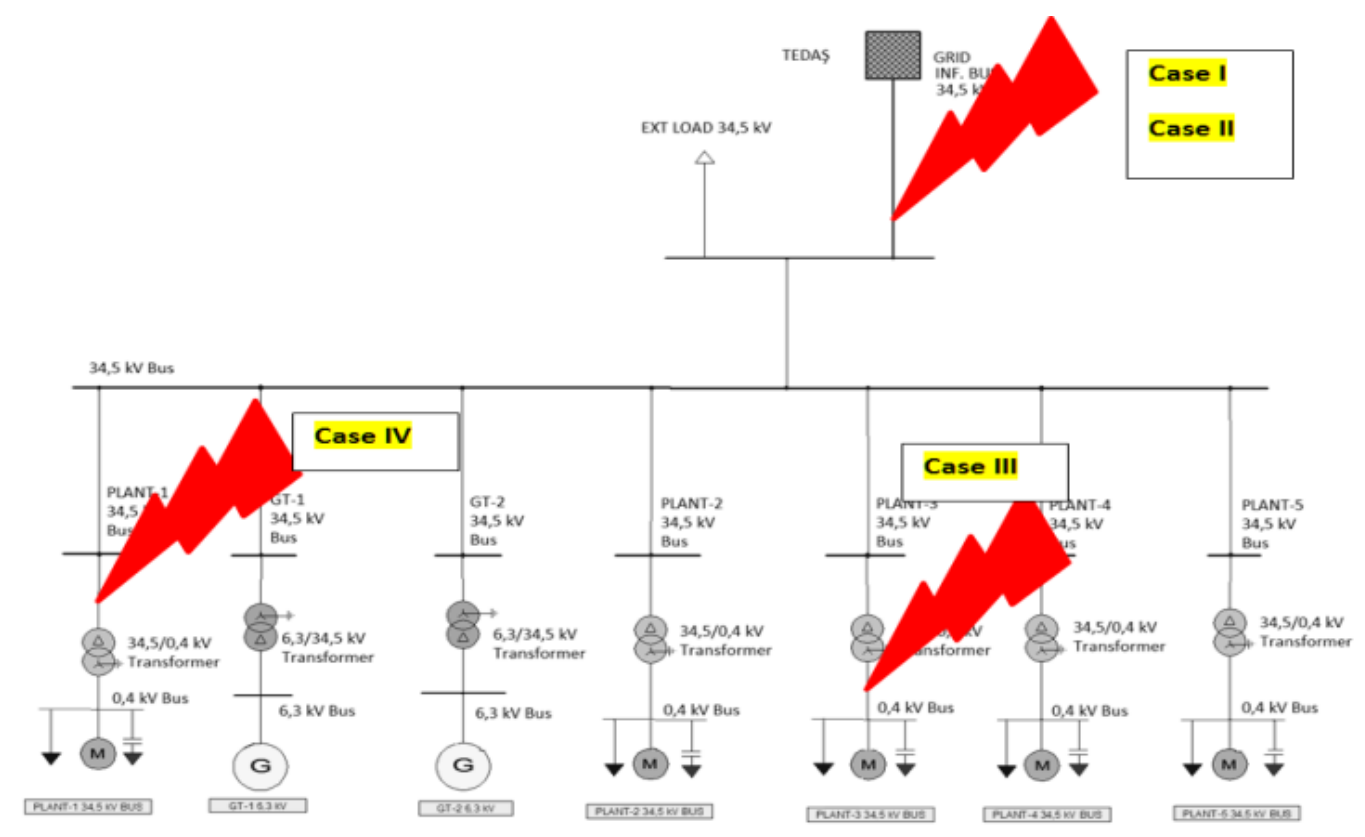

Figure 7. The representation of cases location in simulation single line diagram

The results have been shown according to the currents and voltage signal wave forms measured from the energy analyzers at each bus. The fault was cleared at the 700th msec, the system became steady-state. The results waveform for the single phase ground fault is shown in Figure 8. 


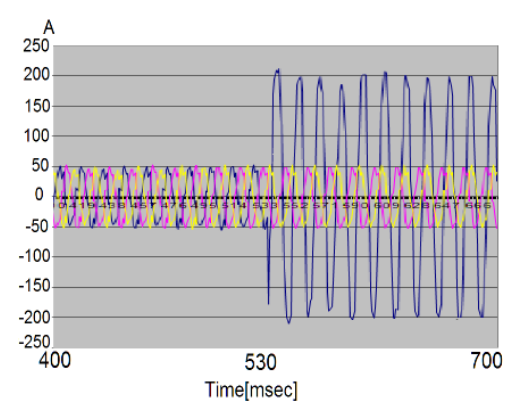

(a)

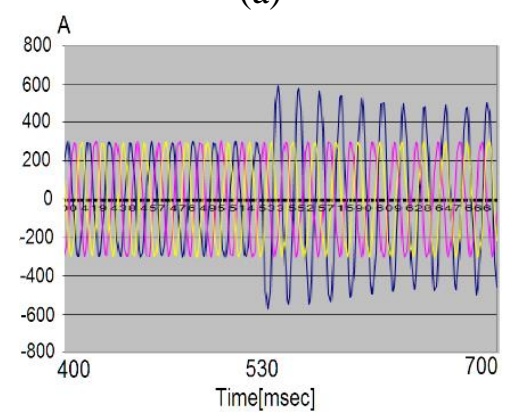

(d)

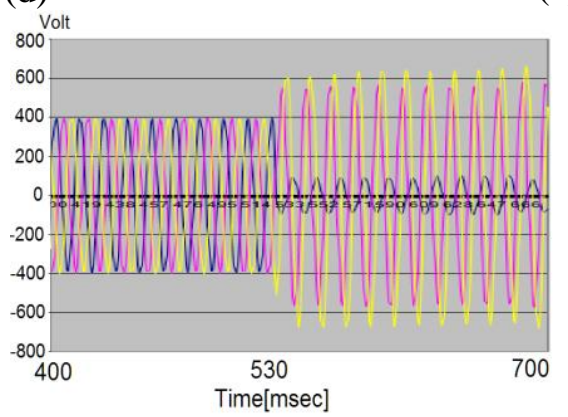

(g)

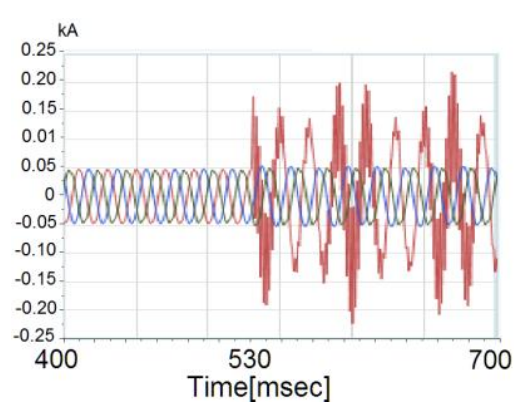

(b)

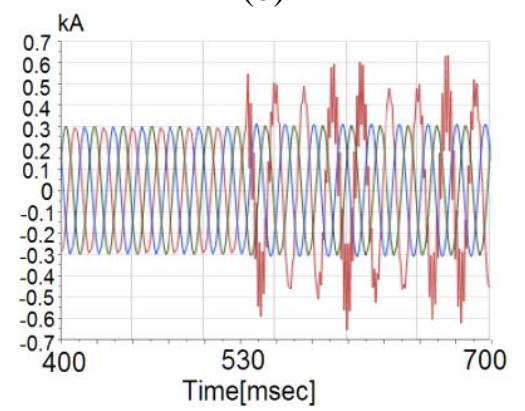

(e)

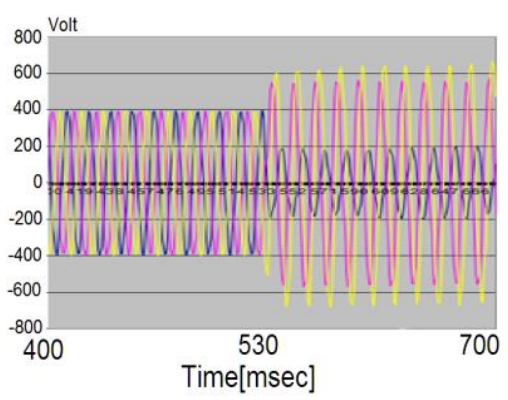

(c)

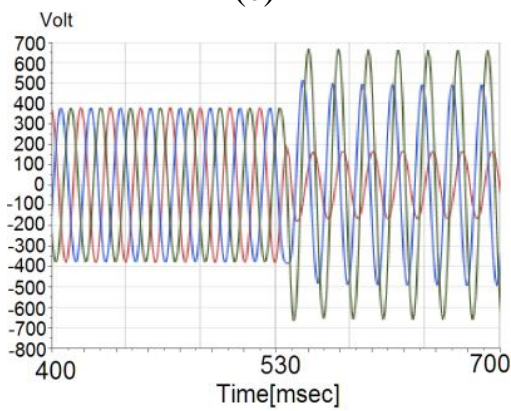

(f)

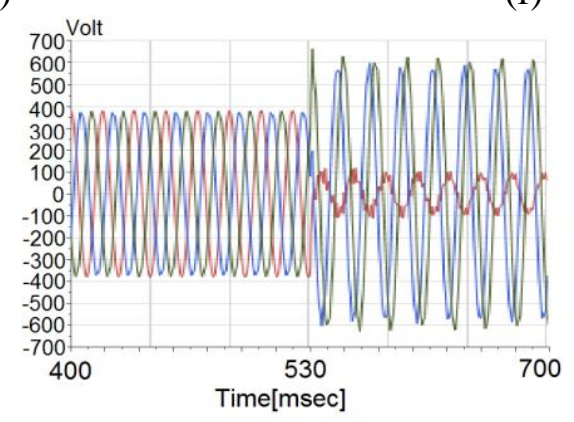

(h)

Figure 8. Case 1 waveforms; a) PCC current (real), b) PCC current (simulation), c) $34.5 \mathrm{kV}$ bus voltage (real), d) GT-2 current (real), e) GT-2 current (simulation), f) $34.5 \mathrm{kV}$ bus voltage (simulation), $g$ ) GT-2 voltage (real) $h$ ) GT-2 voltage (simulation)

It was seen that the current measured at the point of common coupling (PCC) point increased approximately 4 times the normal operating value which increased from approximately $50 \mathrm{~A}$ to $200 \mathrm{~A}$ in Figure 8(a). This situation may change according to the fault impedance at the point where the short circuit occurred. At fault during, only the results of GT-2 and PCC, were compared, since only GT-2 and PCC had measurement results. This time, it was seen that the current of generator 2 doubled. This means that GT2 also supplied the fault current at the fault point. Looking at the voltage results, it was seen that the voltages increase in the phases except the phase where the fault occurred. In other words, while the voltage on the L1 line, which is the fault phase, decreased to $200 \mathrm{~V}$, the voltage increased to around $600 \mathrm{~V}$ in the non-fault phases L2 and L3. This situation has been confirmed by the results in the literature and has been validated with the simulation results.

After validating the accuracy of current and voltage changes that occur in real fault situations, other fault situations that may occur in the power plant are simulated as case- 2 , case- 3 and case- 4 .

Case 2: The 2 phase ground fault circuit occurred at the transmission line between grid and coupling bus at the 200th msec and then the fault was cleared at the 280th msec. The results waveforms for the three phase ground fault are shown in Figure 9.

It was designated as PCC where the fault occurs was almost there. For this reason, in case of a 2 phase fault, the voltage in the faulty phases (L1 and L2) were measured nearly $0 \mathrm{~V}$ in the simulation. On the other hand, the current measured at the PCC increased approximately 9-10 times the nominal 125 A value and supplied 
the fault current close to the generators. The fault current near the generator was gradually decreased in accordance with its typical generator fault current characteristic. In the phase non-fault (L3), it was observed that the current was continuing normally value. Similarly PCC, it was seen that the fault currents increased to 5-6 times in GT-1 and, it was observed that the current was remained.

The voltage in the factory $34.5 \mathrm{kV}$ bus and GT-1 bus dropped from $380 \mathrm{~V}$ to around $200 \mathrm{~V}$. The reason of this, the measured buses are close to GT-1 and supplied from GT-1. The system was supplied to the GT-1 side to ensure voltage stability.

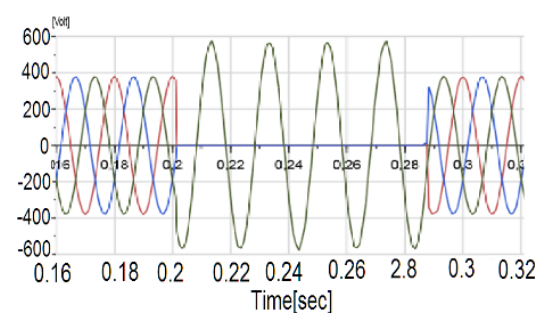

(a)

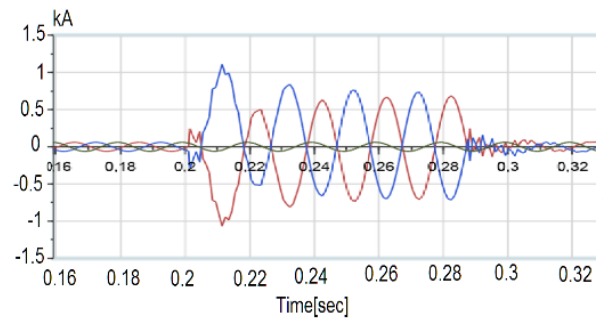

(b)

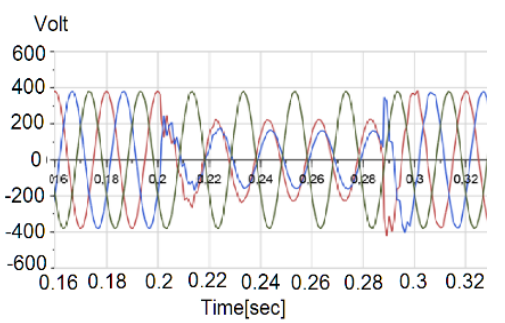

(c)

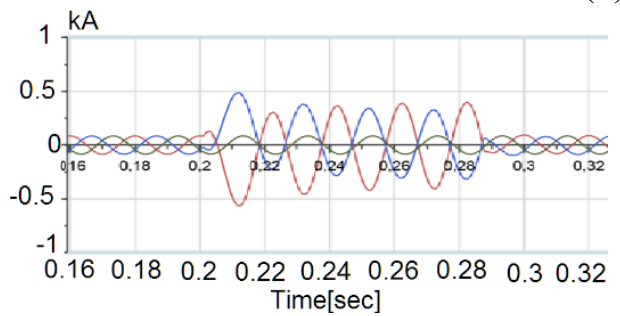

(d)

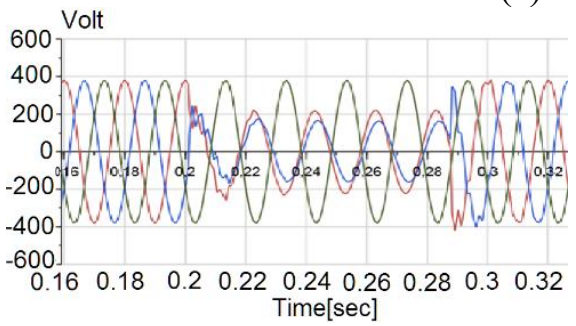

(e)

Figure 9. Case 2 waveforms; a) PCC voltage, b) PCC current, c) GT-1 voltage, d) GT-1 current, e) PCC Bus voltage

Case 3: The 3 phase ground fault circuit occurred at the plant-3 low voltage line low voltage load between the low voltage bus at the 200th msec, and then fault had been cleared at the 280th msec. During the fault, the voltage and current levels are shown as in the Figure 10. The grid and the generator units (GT-1 and GT-2) supplied the short circuit fault by supporting each other. Therefore, when the short circuit occurred, the currents of 3 phase sharply increased from nominal magnitude to 20 times in $0.4 \mathrm{kV}$ low voltage bus. The currents of 3 phase gradually decreased until the fault was cleared. After the 280th msec, the currents decreased fast to the magnitude about nominal level. The system became steady-state at the 330th msec. This means; $50 \mathrm{msec}$ later after the fault was cleared, the system became steady-state. Because GT-1, GT-2 and the grid supplied the fault, there was a great increase in the fault currents in low voltage load. The angle difference between the faults can be negligible.

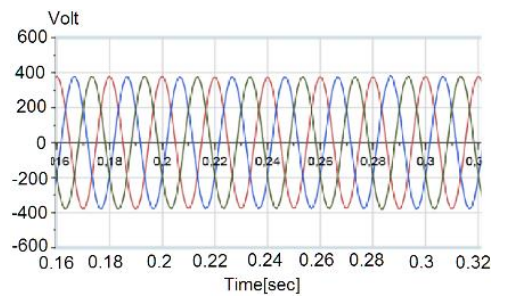

(a)

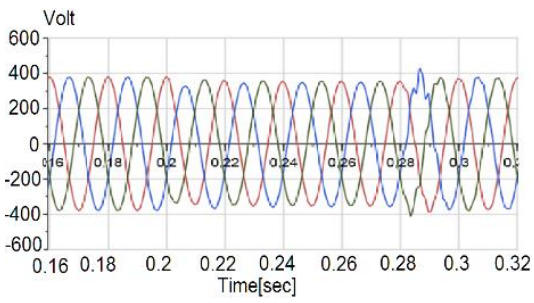

(b)

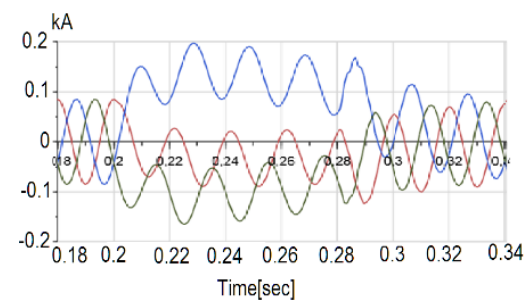

(c) 


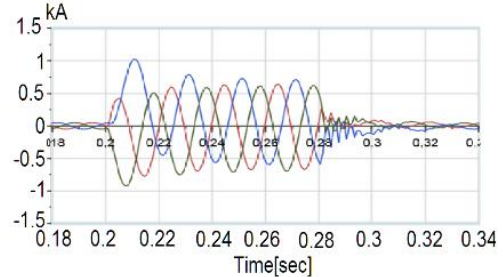

(d)

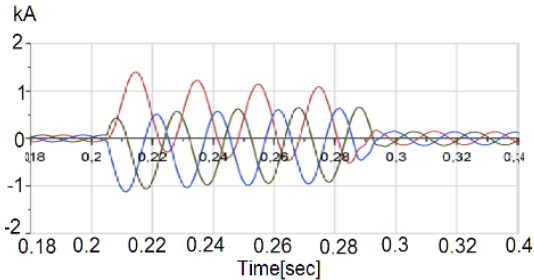

(e)

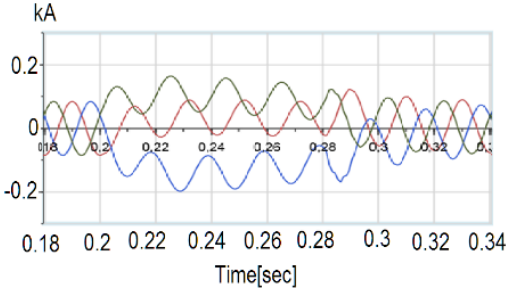

(f)

Figure 10. Case 3 waveforms; a) PCC voltage, b) Plant-1 voltage, c) GT-1 $34.5 \mathrm{kV}$ bus current, d) PCC current, e) Plant-3 $34.5 \mathrm{kV}$ bus current, f) GT-2 $34.5 \mathrm{kV}$ bus level current

The system became steady-state at the 300th msec. This means; $20 \mathrm{msec}$ later after the fault was cleared, the system became steady-state. This period was shorter than the $34.5 \mathrm{kV}$ bus voltage level fault for becoming steady-state. There was some increase in the currents of GT-1 and GT-2 during the fault. When the short circuit occurred, the currents of 3 phase sharply increased from nominal magnitude to 2 times. The currents of 3 phase gradually decreased until the fault was cleared. After the 280th msec, the currents decreased fast to the magnitude about nominal level. The system became steady-state at the $330 \mathrm{msec}$. This means; $50 \mathrm{msec}$ later after the fault was cleared, the system was became steady-state. In addition to GT-1 and GT-2, the grid also supplies the fault.

Case 4: The phase to phase ground fault occurred at plant-1 $34.5 \mathrm{kV}$ bus in island mode operation of power plant at the 200th msec and then fault was cleared at the 280th msec. The voltages of L1 and L2 phases dropped to about $200 \mathrm{~V}$ magnitude. The voltage levels were not zero. The DG sources (GT-1 and GT-2 generator) were very near $34.5 \mathrm{kV}$ bus. There was no deviation voltage of L3 phase. The voltage and current variations measured from the buses and the lines according to the time, when a short circuit at grid occurred, have been shown at below Figure 11.

After the phase L1 to phase L2 short circuit had occurred, L1 and L2 phases voltage sharply dropped to zero volt magnitude. At the same time, L3 phase voltage raised about $600 \mathrm{~V}$ as expected and during the fault, L3 phase remained at constantly magnitude of $600 \mathrm{~V}$. The fault was cleared at the 280th msec but 10 msec after the clearing, the system became steady-state. When the short circuit occurred, the currents of L1 and L2 phases sharply increased from nominal magnitude to 2 times. The currents of L1 and L2 phases gradually decreased until the fault was cleared while L3 phase current magnitude continued nearly normally. GT-1 and GT-2 supplied the fault so there was a big increase in the fault currents in L1 and L2 phases as expected. After the phase L1 to phase L2 short circuit had occurred, the currents of L1 and L2 phases dropped to half of the normal current magnitude. After the fault, L1 and L2 phases continued on the same phase angle until the fault was cleared. All plants were connected to the same bus. Therefore, there was no voltage level difference in the buses of each plant. All of the obtained current waveforms were the same shape as expected. Because all plants had different loads, they had different current level magnitude. 


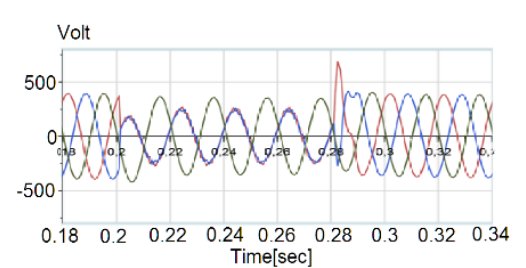

(a)

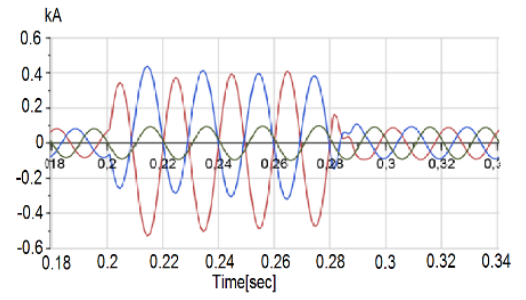

(d)

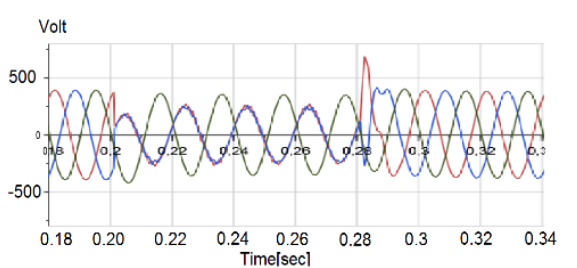

(b)

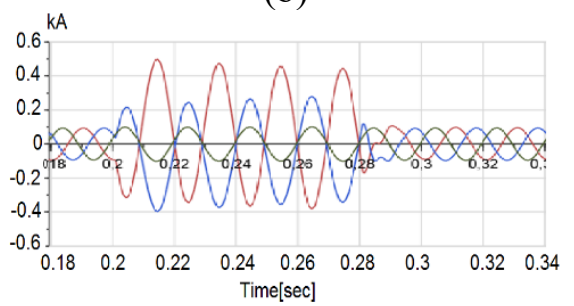

(e)

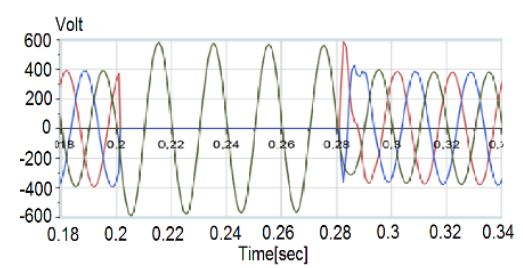

(c)

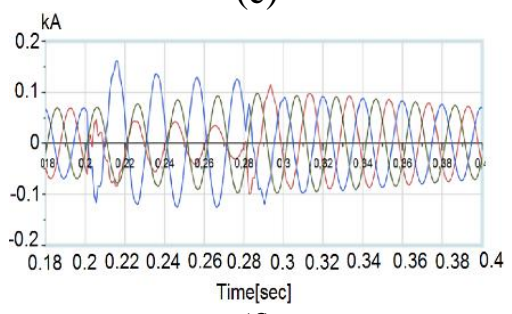

(f)

Figure 11. Case 4 waveforms; a) GT-1 voltage, b) GT-2 voltage, c) Plant-1 bus voltage, d) GT-1 bus current, e) GT-2 bus current, f) Plant-1 bus current

As soon as the short circuit occurred, the currents of L1 and L2 phases sharply increased from nominal magnitude to 5 times. The currents of L1 and L2 phases gradually decreased until the fault was cleared while L3 phase current magnitude continued normally. Since GT-1 and GT-2 supplied the fault direction, there was a big increase in the fault currents in GT-1 and GT-2 as expected. After the beginning of the fault, L1 and L2 phases continued on the same phase angle until the fault was cleared.

\section{CONCLUSION AND FURTHER WORK}

The simulations on modeled power system are practical ways to define the fault currents for a certain condition. It allows the designer to design new power plant as good as plan expansion of existing power plants with higher degree of precision. Considering the prices of protection equipment, which has a large part in system design, this way would allow designer to reduce the cost of the protective equipment. In this study, real fault situation is simulated with the real measured data in cogeneration power plant in IzmirTurkey. The faults have been simulated at four different cases and two operation modes to confirm the effect on the magnitudes of the fault currents and voltages.

The results obtained from after the real fault is very similar to the results obtained by simulation. PSS/Sincal has been shown that short-circuit current contribution of distributed generation. To analyses these features, grid connected cogeneration power plant has been modeled and simulated. After actual short-circuit condition, measured wave form has been analyzed. The reason why the real data and simulation results are very close to each other is because of accurately modeling. For a precisely modeling, the data can be created by using real values instead of assumptions as much as possible. Looking at the simulation states and results, the case simulated as case- 1 is the simulated version of the real system data, shown as real fault condition, in the software environment. It is seen that the real data are almost identical to the data obtained as a result of simulation. In case of real fault condition, it is seen that the fault current measured at the PCC point is shown Figure 8(a) and the short circuit currents observed as a result of the simulation in shown Figure 8(b) almost have the same values. During the fault, it was observed that the nominal current increased approximately 4 times which increased by \% 400 from approximately $50 \mathrm{~A}$ to $200 \mathrm{~A}$. When the other real measurement results obtained from the power plant and not shown in this publication are evaluated, it can reach instantaneous values where the short circuit current increases 10-50 or even 70 times depending on the impedance where the short circuit occurs. Distribution Company (DISCO) is obliged to report only the type of the fault in the power plan, and it does not report its location. For this reason, protection devices should be selected according to the most value when designing power plant. Similarly, when looking at the voltages, as expected, a sharp drop in the voltage was observed in the faulty phase. The closer the measurement is to the fault point, in other words, the closer a fault occurs to the measurement point, the voltage value reaches zero. In case of real fault condition, it can be said that the fault occurred at a distant point in the power plant. The voltage level in the non-fault phases increased by $\% 50$ from $380 \mathrm{~V}$ to around 
$580-600 \mathrm{~V}$. On the other hand, the voltage on the L1 line which is the fault phase, decreased by $\% 47$ from $380 \mathrm{~V}$ to $200 \mathrm{~V}$. As seen from the cases, as the location of the fault gets closer to the generator, the short circuit currents gradually increase. On the other hand, the voltages are gradually decreasing to $0 \mathrm{~V}$. As the location of the fault and its distance from the generator increase, the voltage measured in the DG buses decreases to half the nominal voltage during the fault.

In the light of confirmed data, the results of how the system will respond in other possible fault conditions are obtained in case-2, 3 and 4. It has been emphasized that it is accuracy to simulate before investing and design in a power system in order to prevent the faults during the designing and expansion and working before the installation.

As a future work, during the fault, the stability and frequency change of factories in the grid (on-grid mode) or (off-grid mode) will be modeled in large-power motors operating. Thus, improvement suggestions can be proposed on the fault clearing time.

\section{CONFLICTS OF INTEREST}

No conflict of interest was declared by the authors.

\section{REFERENCES}

[1] Das, T., Roy, R., Mandal, K.K., "Impact of the penetration of distributed generation on optimal reactive power dispatch", Protection and Control of Modern Power Systems, 5(1), (2020).

[2] Guo, J., Ding, X., Wu, W., "A Blockchain-Enabled Ecosystem for Distributed Electricity Trading in Smart City", IEEE Internet of Things Journal, 8(3): 2040-2050, (2021).

[3] Baloch, S., Muhammad, M.S., "An Intelligent Data Mining-Based Fault Detection and Classification Strategy for Microgrid", IEEE Access, 9: 22470-22479, (2021).

[4] Pesaran H.A.M., Huy, P.D., Ramachandaramurthy, V.K., "A review of the optimal allocation of distributed generation: Objectives, constraints, methods, and algorithms", Renewable and Sustainable Energy Reviews, 75(May 2016): 293-312, (2017).

[5] Haider, W., Ul Hassan, S.J., Mehdi, A., Hussain, A., Adjayeng, G.O.M., and Kim, C.H., "Voltage profile enhancement and loss minimization using optimal placement and sizing of distributed generation in reconfigured network", Machines, 9(1): 1-16, (2021).

[6] Karimi, M., Farshad, M., Hong, Q., Laaksonen, H., and Kauhaniemi, K., “An Islanding Detection Technique for Inverter-Based Distributed Generation in Microgrids", Energies, 14(1): 130, (2020).

[7] Zheng, T., Yang, H., Zhao, R., Kang, Y.C., and Terzija, V., "Design, evaluation and implementation of an islanding detection method for a micro-grid", Energies, 11(2): 323, (2018).

[8] Pinto, J.O.C.P., and Moreto, M. "Protection strategy for fault detection in inverter-dominated low voltage AC microgrid", Electric Power Systems Research, 190(August 2020): 106572, (2021).

[9] Kim, I., "A calculation method for the short-circuit current contribution of current-control inverterbased distributed generation sources at balanced conditions", Electric Power Systems Research, 190 (August 2020): 106839, (2021).

[10] Xiao, H., Ren, S., and Li, Y., "Novel disturbance blocking criterion for reliable current differential protection of LCC-HVDC lines", IEEE Transactions on Power Delivery, 36(1): 477-480, (2021). 
[11] Gao, S.P., Liu, Q., and Song, G.B., "Current differential protection principle of HVDC transmission system", IET Generation, Transmission and Distribution, 11(5): 1286-1292, (2017).

[12] Zarei, S.F., and Khankalantary, S., "Protection of active distribution networks with conventional and inverter-based distributed generators", International Journal of Electrical Power and Energy Systems, 129(June 2020): 106746, (2021).

[13] Sahito, A.A., Halepoto, I.A., Uqaili, M.A., Memon, Z.A., Larik, A.S., and Mahar, M.A., “Analyzing the Impacts of Distributed Generation Integration on Distribution Network: A Corridor Towards Smart Grid Implementation in Pakistan", Wireless Personal Communications, 85(2): 545-563, (2015).

[14] Avagaddi, P., and Edward J, B., "Fault classification in transmission systems using wavelet transform", Gazi University Journal of Science, 32(3): 884-893, (2019).

[15] Shobole, A., Baysal, M., Wadi, M., and Tur, M.R., "Protection Coordination in Electrical Substation Part-2 Unit Protections (Differential and Distance Protection) -Case Study of Siddik Kardesler Substation (SKS), Istanbul, Turkey", Gazi University Journal of Science, 30(4): 163-178, (2017).

[16] Ayvaz, A., and Boylu, A.B., "Determination of optimal placement of fault current limiting device against short circuit faults occur in power systems", Sakarya University Journal of Science, 22(2): 615-623, (2018).

[17] Alasali, F., El-Naily, N., Zarour, E., and Saad, S.M., "Highly sensitive and fast microgrid protection using optimal coordination scheme and nonstandard tripping characteristics", International Journal of Electrical Power and Energy Systems, 128(October 2020): 106756, (2021).

[18] Chandraratne, C., Ramasamy, T.N., Logenthiran, T., and Panda, G., "Adaptive protection for microgrid with distributed energy resources", Electronics (Switzerland), 9(11): 1-14, (2020).

[19] Yalcin, F., and Yildirim, Y., "A Study of Symmetrical and Unsymmetrical Short Circuit Fault Analyses in Power Systems", Sakarya University Journal of Science, 23(5): 879-895, (2019).

[20] Rustemli, S., and Demir, I., "Analysis and simulation of single phase-to-ground short circuit fault in Van $154 \mathrm{kV}$ substation: An experimental assessment", Bitlis Eren University Journal of Science and Technology, 9(2): 76-82, (2019).

[21] Patil, B., and Namekar, S., "Load Flow \& Short Circuit Analysis of 132/33/11KV Substation using ETAP", International Journal of Applied Engineering Research, 13(11): 9943-9952, (2018).

[22] Hosseini, S.A., Sadeghi, S.H.H., and Nasiri, A., "Decentralized Adaptive Protection Coordination Based on Agents Social Activities for Microgrids with Topological and Operational Uncertainties", IEEE Transactions on Industry Applications, 57(1): 702-713, (2021).

[23] Ballal, M.S., and Kulkarni, A.R., "Improvements in Existing System Integrity Protection Schemes under Stressed Conditions by Synchrophasor Technology -Case Studies", IEEE Access, 9(2021).

[24] Muljadi, E., and Gevorgian, V., "Short-circuit modeling of a wind power plant" , IEEE Power and Energy Society General Meeting, 1-9, (2011).

[25] Devi, M.M., Geethanjali, M., and Devi, A.R., "Fault localization for transmission lines with optimal Phasor Measurement Units", Computers and Electrical Engineering, 70: 163-178, (2018).

[26] Asija, D., Choudekar, P., Singla, R., and Chouhan, M., "Performance Evaluation and Improvement in Transient Instability of IEEE 9 Bus System Using Exciter and Governor Control", Procedia Computer Science, 70: 733-739, (2015). 
[27] Khatua, S., and Mukherjee, V., "Adaptive overcurrent protection scheme suitable for station blackout power supply of nuclear power plant operated through an integrated microgrid" , Electric Power Systems Research, 192(March 2020): 106934, (2021).

[28] Balamurugan, K., Srinivasan, D., and Reindl, T., "Impact of distributed generation on power distribution systems", Energy Procedia, 25: 93-100, (2012).

[29] Shin, H., Chae, S.H., and Kim, E.-H., "Design of Microgrid Protection Schemes Using PSCAD/EMTDC and ETAP Programs", Energies, 13(21): 5784, (2020).

[30] Nadeem, M.H., Zheng, X., Tai, N., Gul, M., Yu, M., and He, Y., "Non-communication based protection scheme using transient harmonics for multi-terminal HVDC networks" , International Journal of Electrical Power \& Energy Systems, 127: 106636, (2021).

[31] Darwish, A., Abdel-Khalik, A.S., Elserougi, A., Ahmed, S., and Massoud, A. "Fault current contribution scenarios for grid-connected voltage source inverter-based distributed generation with an LCL filter”, Electric Power Systems Research, 104: 93-103, (2013).

[32] Song, J., Li, Y., and Zhang, Y., "Fault steady-state analysis method for the AC system with LCCHVDC infeed", Electric Power Systems Research, 192: 106994, (2021).

[33] Bendjabeur, A., Kouadri, A., and Mekhilef, S., "Transmission line fault location by solving line differential equations", Electric Power Systems Research, 192: 106912, (2021).

[34] Moustafa, M.A.M.M., and Chang, C., "Preventing cascading failure of electric power protection systems in nuclear power plant", Nuclear Engineering and Technology, 53(1): 121-130, (2021).

[35] El-Khattam, W., and Salama, M.M.A., "Distributed generation technologies, definitions and benefits" , Electric Power Systems Research, 71(2): 119-128, (2004).

[36] Bawazir, R.O., and Cetin, N.S., "Comprehensive overview of optimizing PV-DG allocation in power system and solar energy resource potential assessments", Energy Reports, 6: 173-208, (2020).

[37] Dondi, P., Bayoumi, D., Haederli, C., Julian, D., and Suter, M., "Network integration of distributed power generation", Journal of Power Sources, 106: (1-2): 1-9, (2002).

[38] Pepermans, G., Driesen, J., Haeseldonckx, D., Belmans, R., and D'haeseleer, W., "Distributed generation: Definition, benefits and issues", Energy Policy, 33(6): 787-798, (2005).

[39] Ochoa, L.F., Padilha-Feltrin, A., and Harrison, G.P., "Evaluating distributed generation impacts with a multiobjective index", IEEE Transactions on Power Delivery, 21(3): 1452-1458, (2006).

[40] Farzinfar, M., and Jazaeri, M., "A novel methodology in optimal setting of directional fault current limiter and protection of the MG", International Journal of Electrical Power and Energy Systems, 116 (September 2019): 105564, (2020).

[41] Alcala-Gonzalez, D., Del Toro, E.M.G., Más-López, M.I., and Pindado, S., "Effect of distributed photovoltaic generation on short-circuit currents and fault detection in distribution networks: A practical case study", Applied Sciences (Switzerland), 11(1): 1-16, (2021).

[42] Boutsika, T.N., and Papathanassiou, S.A., "Short-circuit calculations in networks with distributed generation”, Electric Power Systems Research, 78(7): 1181-1191, (2008).

[43] Dincer, I., and Rosen, M.A., Cogeneration, Multigeneration, and Integrated Energy Systems, in: 
Exergy Analysis of Heating, Refrigerating and Air Conditioning, 2015: 69-219, (2015).

[44] Ghaedi, A., and Golshan, M.E.H., "Modified WLS three-phase state estimation formulation for fault analysis considering measurement and parameter errors", Electric Power Systems Research, 190 (March 2020): 106854, (2021).

[45] Yang, S., and Tong, X., "Integrated power flow and short circuit calculation method for distribution network with inverter based distributed generation" , Mathematical Problems in Engineering, 2016 (2016).

[46] Baran, M.E., and El-Markaby, I., "Fault Analysis on Distribution Feeders With Distributed Generators", IEEE Transactions on Power Systems, 20(4): 1757-1764, (2005).

[47] Abdel-Akher, M., and Nor, K.M., "Fault analysis of multiphase distribution systems using symmetrical components", IEEE Transactions on Power Delivery, 25(4): 2931-2939, (2010).

[48] Strezoski, L. V., and Prica, M.D., "Short-circuit analysis in large-scale distribution systems with high penetration of distributed generators" , IEEE/CAA Journal of Automatica Sinica, 4(2): 243-251, (2017).

[49] Abdel-Akher, M., and Nor, K.M., "Fault Analysis of Multiphase Distribution Systems Using Symmetrical Components", IEEE Transactions on Power Delivery, 25(4): 2931-2939, (2010).

[50] PSS/SINCAL (SIEMENS Network Calculation) software, "Introduction to the System Manual", (2014).

[51] https://new.siemens.com/global/en/products/energy/services/transmission-distribution-smartgrid/consulting-and-planning/pss-software/pss-sincal/pss-sincal.html\#Electricitymodules. Access date: 17.07 .2020 